\title{
Uma reflexão sobre o indizível do corpo e suas articulações com a linguagem: por uma pedagogia da decomposição
}

Rejane Kasting Arruda ${ }^{1}$

Universidade de São Paulo - USP

"Da decomposição do todo de um gênero em seus elementos isolados surgem as novas linguagens formais" (LEHMANN, 2007, p. 83). É a decomposição que propomos como estratégia para uma pedagogia da criação, quando elegemos, na Universidade de São Paulo, em pesquisa continuada junto ao Centro de Pesquisa em Experimentação Cênica do Ator ${ }^{2}$, certos campos de extração de materiais com os quais o ator explora a perspectiva de encenar. Trata-se da pesquisa $O$ ateliê do ator-encenador, orientada por Silva, que lança mão do que nomeamos "anteparos" : materiais que fazem incidência sobre o corpo, instalando uma sucessão de impulsos.

Utilizamos a criação como método de pesquisa. O espetáculo criado se configura como um documento, a partir do qual a reflexão será aprofundada. Ao mesmo tempo em que a prática depende de uma formalização teórica que a oriente e a constitua, a teoria engendrada implica a observação de funções e operações advindas dessa prática. De maneira que, além da singularidade de cada processo de criação, se evidenciam funções e operações que, postas em diálogo com a teoria teatral já constituída, nos ajudam a formalizar uma estrutura. Esperando contribuir para a transmissão da experiência cênica e a sua formalização, apostamos, também, na singularidade de uma criação que, apesar de implicar a estrutura que nos esforçamos a formalizar, lança mão de campos específicos de extração de materiais.

As diferentes escolas, estilos ou modalidades de criação ou pedagogia não são tomadas como dicotômicas, mas como campos específicos de extração de materiais - que lançamos mão em novas experiências. Sem saber qual estética será originária destas novas experiências, nos colocamos em função dos anteparos, que podem ser categorizados em: imagem, palavra, objeto e movimento ${ }^{4}$. O que Silva nomeia “impressão digital” será, então,

\footnotetext{
${ }^{1}$ Atriz e pesquisadora na Universidade de São Paulo, integrante do Centro de Pesquisa em Experimentação Cênica do Ator, desde 2006, onde realiza pesquisa de doutoramento com apoio da FAPESP e orientação do Prof. Dr. Armando Sergio da Silva. Estuda psicanálise no Fórum do Campo Lacaniano. E-mail: rejane7karruda@yahoo.com.br.

${ }^{2}$ O Centro de Pesquisa em Experimentação Cênica do Ator é um projeto do Departamento de Artes Cênicas da Escola de Comunicações e Artes da Universidade de São Paulo.

${ }^{3}$ Ver Arruda (2010b); Silva (2010).

${ }^{4}$ Estamos propondo, além da imagem, palavra e objeto (já modalizados por Silva), também o movimento
} 
a resultante, sempre fresca e instantânea, do ato cênico, que implica "a tomada de corpo" desses anteparos. A inscrição do corpo em cena se constitui como resultante dos deslocamentos, condensações, substituições ou apagamentos dos materiais - para que algo que resta das operações se fixe no corpo, encenando-o.

Como o corpo pode ser enquadrado em cena é uma questão que se coloca. Certos materiais são usados justamente para isso. No Ateliê do ator-encenador lançamos mão, por exemplo, de formas variadas da exposição da palavra para este enquadre: além da enunciação através da fala, a pichação nas paredes, a projeção da grafia das palavras e a sua sonorização (com a sonoplastia). O corpo, enquadrado pela palavra "externa", também sofre a incidência quando esta não está exposta. Nesse caso, trata-se da palavra "interna": uma imagem acústica (como quando cantamos mentalmente uma música) ou impregnação no corpo (enquanto produção pulsional).

A articulação entre o verbo e a pulsão se encontra formalizada na psicanálise de orientação lacaniana. Segundo Soler (2010, p. 13), "as pulsões são um eco do fato de que há um dizer". O verbo não é constituído apenas da linguagem (que, enquanto lugar do significante, implica o jogo de deslocamentos e efeitos de significação), mas da "alingua". Essa noção, forjada por Lacan no final do seu ensino, trata especialmente do que se goza no verbo: os estilhaços de som sem sentido que não fazem conjunto, não entram na estrutura - se remetendo à ordem do Real (do indizível) e implicando articulação entre linguagem e gozo. Além disso, o significante goza do corpo, sendo passado à letra e implicando, também, o entroncamento entre linguagem e real: "o significante está ao nível do gozo" (Idem, ibidem). De maneira que é possível vislumbrar que há gozo no ato de repetir uma escrita de palavras e presentificar o seu encadeamento acústico, abrindo a perspectiva de associações com imagens internas. A repetição marca um ritmo corporal. De maneira que, memorizada, a "fala interna" ${ }^{5}$ impregna o corpo de pulsão, instalando o que, na teoria teatral, nomeamos "impulso" para a ação.

Trata-se do procedimento desenvolvido em pesquisa de mestrado realizada por esta pesquisadora (intitulada Apropriação de texto: um jogo de imagens) ${ }^{6}$, que toma a Memorização através da escrita, difundida no Brasil por François Khan e Cacá Carvalho ${ }^{7}$, como um ponto

como uma modalidade de anteparo - já que este pode ser isolado, repetido, rememorado e composto com outros em diferentes arranjos (e diferentes resultantes).

5 Retomamos a noção de fala interna kusnetiana. No entanto, isolamos este elemento da lógica da personagem que, no caso de Kusnet, opera a sua criação. Ver Kusnet (1992).

6 Esta pesquisa está documentada em Arruda (2009a); Arruda (2010a); e, ainda, em Arruda (2009b).

${ }^{7}$ François Khan reflete sobre este procedimento em Khan (2009). 
de partida. Partimos da memorização de um texto falado e da descrição das operações quando jogamos o texto junto a partituras físicas de modalidades diferentes. O segundo passo da experiência foi observar que o desenho corporal poderia ser sustentado por palavras internas que, em foco, aumentavam a intensidade da ação. As ações físicas foram reduzidas. Ficamos, apenas, com o impulso no corpo, enquanto o foco se dividia com a sonoridade da fala (trabalhávamos, então, com o texto Quarteto, de Heiner Müller). O terceiro passo foi mudar as regras do jogo depois de memorizar (com a repetição da escrita) a partitura de falas internas que isolamos. Ao invés de presentificar a partitura física já constituída, nos propomos a improvisar com "instruções de jogo" - "fazer gestos grandes" e "ocupar todo o espaço" (além das falas internas) -, que se revezavam no foco. As ações físicas antes constituídas retornaram, no entanto, em lugares diferentes, formando uma outra composição. Percebemos uma nova perspectiva do uso da Memorização através da escrita: a memorização não do texto falado, mas da fala que não se enuncia (e que vibra internamente). Esta, segredada e em relação com regras diferentes de jogo, presentifica materiais corporais de maneira antes impensada.

O quarto passo da pesquisa foi memorizar, com a repetição da escrita, o que passamos a chamar "descrição de corpo": a descrição de um encadeamento de ações físicas. Promovemos mais um deslocamento: da memorização da fala externa para a memorização da fala interna e, por fim, da descrição de corpo. Percebemos que memorizar a descrição de corpo nos permitia determinar um encadeamento fixo com o qual poderíamos improvisar variações. Como tínhamos os impulsos (pois durante a memorização o corpo é impregnado pela pulsão), poderíamos fazer algo diferente do que era a partitura original se houvesse um arranjo com outros materiais. Por exemplo, alterando a música, o texto falado, o objeto em cena ou a fala interna, a resultante seria outra. De maneira que o conceito de "anteparo" (como material que faz incidência no corpo) passou a nos orientar na pesquisa de doutorado que se iniciava: objeto, imagem, palavra e movimento se harmonizavam e convergiam para resultantes que se produziam como resto de operações de convergência ou atrito (e divisão de foco) ${ }^{9}$.

\footnotetext{
8 Tomamos a noção de instrução de jogo de Viola Spolin, que implica de impulso para a ação: "a instrução atinge o organismo total” (SPOLIN, 2004, p. 25). Enquanto elemento passível de isolamento e composição, a tomamos como um anteparo da modalidade palavra. Junto a outros, a instrução faz incidência no corpo. Haverá, então, um resto da operação que instala a "impressão digital" em cena (que o ator percebe a posteriori). 9 Divisão de foco é uma operação presente em Spolin. Manejamos a divisão de foco para multiplicar impulsos. Isso na medida em que o foco, dividido, desliza entre materiais diferentes. Cada troca resulta em novo impulso. Ver Arruda (2009b).
} 
Elegemos campos de extração ${ }^{10}$ de anteparos. A performance foi um deles, assim como o romance Minha vida, escrito por Nelson Rodrigues sob o pseudônimo de Suzana Flag. O campo da performance nos ofereceu imagens e objetos que misturamos com outras imagens e, também, palavras do romance. Os objetos foram manejados para provocar efeitos de significação que poderiam articular o enredo: uma escada significava um homem, assim como um aquário (composto com chapéu e sapato). Ao mesmo tempo, o enredo (elemento do romance) foi tomado, também, como campo específico de extração de materiais isolados e heterônimos. Frases escritas nas paredes passaram a se constituir como parte de uma poética de enquadres do corpo que contou, também, com a música, o som da voz e o movimento - que evocava ação, imagem e pensamento -, de maneira que se colocou em questão o arranjo dos elementos presentes em um instante cênico.

Lehmann pontua o divórcio entre texto e teatro que caracteriza o pós-dramático, bem como a autonomia do teatro: "a interpretação do papel e o ato de se dirigir ao público são tratados como realidades autônomas, o espaço sonoro e o espaço da atuação são separados" (LEHMANN, 2007, p. 83). Ao falar da "autonomização das camadas individuais" e separação dos "aspectos antes colados da linguagem e do corpo", ele se refere (como "linguagem") à palavra advinda do texto. E é, então, que devemos nos perguntar sobre a linguagem que transpassa o corpo e a perspectiva deste se dar a ler, ao mesmo tempo em que consideramos que um texto (literatura ou poesia verbal) - com seus efeitos de significação - não traduz o "indizível” implicado na estrutura poética. Se a poesia das palavras trabalha o não-dito (que, no jogo desta poética específica é constituído por palavras), não haveria uma ordem indispensável tanto na poética do verbo quando na poética do acontecimento de corpo, este "indizível”? Por outro lado, se é possível escutar um corpo (o que evidencia a presença da linguagem), ainda assim é evidente que trabalhamos a sua poética em função do reconhecimento do que não se pode escutar ou dizer. Percebe-se, portanto, que a poética que se vale de um acontecimento de corpo, assim como a poética que se vale do verbo, trabalha tanto com a linguagem quanto com o que dela escapa.

Para a psicanálise de orientação lacaniana, o que escapa é o Real: “o indizível”, o “impossível”, o que não tem inscrição na linguagem, o que falta ou excede, que não se pega e insiste. Um Real de uma "diz-mansão" (LACAN, 2003, p. 21), dimensão da linguagem. Evidencia-se o enodamento entre linguagem e o que dela escapa e, ainda, essas duas ordens

${ }^{10}$ Estamos propondo este termo. 
com uma terceira: o imaginário (o que faz sentido). O jogo do significante, com as suas ambiguidades e entrelinhas, enoda-se tanto às imagens que nos fascinam quanto ao impossível de se imaginarizar (o opaco que resiste a qualquer significação) ${ }^{11}$. Ou seja, considerando-se este enodamento estrutural, será que a autonomia da cena do corpo deve ser fundamentada em oposição à presença da palavra que advém de um texto? Um outro jeito de defendê-la seria pontuando a dimensão viva do corpo. No entanto, esta, em parte, pode ser verbalizada (inscrita em um jogo de significantes). O significante constrói o mundo do que é escutado e interpretado; constrói, também, o que é lido no corpo e não está dito, mas desliza, condensa, desloca, articula, em um jogo de sucessivas montagens. Se o corpo se produz em um jogo de presença-ausência (de significantes), em que medida algo fica fora da elaboração simbólica? Na medida em que, justamente, o corpo é habitado por uma linguagem enodada ao que lhe escapa?

A poesia (escrita no papel) implica a dimensão do jogo de presença-ausência de palavras - que não foram ditas ou que foram cortadas, apagadas, rasuradas, condensadas, substituídas, deslocadas. Se tanto o corpo quanto a poesia no papel implicam deslizamentos de elementos que podemos nomear significantes (pois se trata do que se troca, ou seja, a ordem do simbólico), o que faz a singularidade da presença do corpo em cena? $\mathrm{O}$ fato do corpo ser de um "fala-ser" (um ser que habita a linguagem) não é um tanto misterioso? E que esta linguagem, por vezes, pare - que nela haja buracos - não nos indica que é justo esta falha que o corpo poetizado representa? Será que não é o lugar da falta (na linguagem) que o corpo (de carne) ocupa? Onde está a falta da poesia falada? Será que não está no corpo do poeta? No corpo de quem lê? Esquecemos que a poesia escrita tem um corpo presente: o de quem escreve (primeiro) e, depois, o de quem lê - em que palavras vibram (fazendo eco, música, sopro). E que palavras sopram a vida daquele corpo? Serão as ditas ou o vazio em torno do qual circulam? Não será o que sobra das articulações entre o dito e o que, por associação, é evocado (e não chega a significar) esta flauta que sopra o corpo? O que faz o teatro senão colocar em cena este buraco que a vibração corporal ocupa? Não é exatamente a forma do corpo que nos impressiona, ou é? O desenho do corpo? O desenho do corpo enquadrado no tempo-espaço é algo que hipnotiza, fascina. Mas há a incidência no organismo; uma vibração, descarga do (poderíamos dizer) gozo.

De maneira que gostaríamos de propor a formalização de duas funções: o que faz

\footnotetext{
${ }^{11}$ Ver Lacan (2007).

12 Termo criado por Lacan.
} 
incidência no corpo (o faz vibrar); e o desenho do corpo no tempo-espaço, que fascina (o espectador) por sua imagem: enquadramento. São duas funções diferentes que queremos destacar e manejar para a composição poética do corpo, com ou sem palavras advindas de um texto prévio. De maneira que a escolha do texto para a extração de anteparos define uma modalidade que, apesar de específica, não implica dicotomia em relação às outras que utilizam outros campos de extração de anteparos - pois se percebe uma mesma estrutura da prática. Por se tratar de uma mesma estrutura (a articulação da função da incidência com a função do enquadramento), o aluno pode misturar campos diferentes de extração e se dedicar à experimentação de novas modalidades da poética cênica.

A relação que a palavra dita vai assumir com o corpo - ou como um arranjo de anteparos vai ser constituído - é uma questão complexa. Como a leitura das palavras - que, ditas, implicam entrelinhas, desejo, interpretação, singularidade (pois cada um lê de um jeito as palavras) - se articula com a interpretação, leitura e entrelinhas dos significantes que se escuta do corpo presente? E como o que escapa a esta articulação faz, no espectador, um efeito; efeito no sentido de que "algo o causa"? Como o que escapa "nos causa"? "Causar" é o quê? Causar desejo - por faltar. A linguagem falta na leitura da cena - com ou sem palavras presentes. O que escapa nos causa e faz procurar. De maneira que deveríamos preservar o não-dito, com ou sem palavras presentes? Como se faz a articulação entre os anteparos que enquadram o corpo para que um não-dito se preserve, uma falta, "causação", desejo? Não podemos dizer que um texto de Heiner Muller não "nos cause". Por mais verborrágico que seja, tanto deixa escapar! Não podemos dizer que o texto encenado de um Tchekhov não seja poético; ou de um Strindberg, Nelson Rodrigues, Pirandello etc. Da mesma maneira, não podemos dizer que o teatro de imagens de Wilson ou Bausch não nos cause! Há algo que está na estrutura do poético e que, no caso da cena teatral, implica a presença do corpo.

Como o corpo, que é singular, se configura como uma poética específica? Será o fato de haver um elemento de contingência? E se, de fato, não conhecemos a linguagem que habita o corpo? E se, de fato, o corpo representa algo que se configura como "um outro"? Se o corpo pode "nos levar" para lugares antes não planejados ou não imaginados previamente pela via da linguagem, o que há no corpo que nos leva? Não seriam os significantes que não ouvimos? Ou haveria traços de gozo? Seriam marcas antigas? Seriam marcas atreladas a questões antigas? Ou seria um desejo posto no outro - este outro que olha? Não seria o desejo de mostrar a incidência que nos move? Não seria um desejo de 
mostrar ao outro que somos assujeitados (com o nosso corpo) ao que nos leva? E seria "por nosso corpo" que somos assujeitados ou pela linguagem cênica onde nos inscrevemos? É interessante pensar na linguagem cênica (corporal) como uma operação de significantes: pequeno e grande, rápido e lento, leve e pesado; denso ou superficial, preciso ou informe, ou quantos pares poderíamos propor, inscritos na linguagem cênica. Há uma linguagem (cênica) que nos antecede; antecede o corpo que, nela, será inscrito. Não podemos nos esquecer que o teatro constrói significantes: "extra-cotidiano", por exemplo. Há linguagem constituindo o corpo que se pretende cênico - e há, também, o que dela escapa.

É importante que se continue criando significantes para o corpo que se pretende cênico. Se a linguagem da poesia escrita se vale da palavra, a linguagem do corpo escrito em cena também. A especificidade é que, no caso da cena, o corpo está à frente: ele esconde as palavras e se constitui como semblante. Como semblante, ele ocupa o lugar de um buraco, ao ponto de pensarmos: lá não há palavras; lá a coisa é muda. O corpo ocupa a cena, puxa o olho. No entanto, será sempre uma mancha no quadro. Seja o quadro que o público canta na sua imaginação ou o quadro que ele, o corpo, ocupa, pintado em cena (como em um Wilson). A cena do corpo implica a leitura e o enquadre; a cena do corpo implica a fragmentação que a linguagem sustenta: lá há dois olhos, um braço, um quadril que se mexe de certa maneira, os cabelos, o jeito de caminhar, o tônus diferente, os movimentos que tomam conta do espaço, explodem no ar, os traços, o vestido. A cena do corpo depende do olhar do espectador - que lê; a cena do corpo implica, no entanto, o que ele não pode ler (assim como o poema). A diferença é que, no teatro, o corpo toma para si esta cena, ele "a positiva"; ele se faz inteiro cena e, como um estranho à linguagem, atesta que algo sobra e faz volume, irrompe. Se o corpo trabalha com a dimensão da incidência no vivo, ele o mostra. Enquanto o corpo de quem lê ou escreve um poema no papel está longe dos olhos de um outro, há cem olhos para ver a incidência no corpo do ator - o que o torna cênico. O corpo cênico "positiva" a incidência da "falta-a-ser" ${ }^{13}$ que a linguagem implica - no vivo - e o gozo enquanto irrupção do não-dito, impossível, indizível, Real.

Voltamos, depois disto, para a primeira proposição de Lehmann que sublinhamos: "Da decomposição do todo de um gênero em seus elementos isolados surgem as novas linguagens formais" (LEHMANN, 2007, p. 83). O que aconteceria se decompuséssemos a estética grotowskiana, stanislavskiana, craigiana, meyerholdiana, spoliana, kusnetiana,

\footnotetext{
13 Termo criado por Lacan.
} 
barbiana etc, em seus elementos mínimos e, apropriando-nos de cada um deles, em função da experimentação, os misturássemos? Segundo Lehmann, o divórcio entre texto e teatro significa "a entrada do teatro na época da experimentação" (Idem, p. 81). Para uma pedagogia do ator, acredito ser esta uma estratégia interessante: decompor as diferentes estéticas e propor, ao aluno, a vivência da experimentação com novas misturas.

Não se nega a importância da preservação das estéticas em sua singularidade, bem como a sua práxis e pensamento - já que a tradição só pode ser transmitida se valorizarmos o conjunto dos elementos de cada uma delas. Há artistas se dedicando ao resgate, transmissão, continuidade e desenvolvimento de certas linhas de trabalho e isso tem o seu valor. No entanto, isso implica, também, a perpetuação de um estilo - no que a palavra "estilo" implica, justamente, de indizível. Implicando o que não pode ser traduzido, o estilo está perto do Real. O artista escreve o impossível de sua obra criando um estilo. Descobrir novos estilos, ou um estilo próprio de atuação ou encenação, significa experimentar, com elementos decompostos da práxis, uma nova maneira de escrever o impossível do corpo. Essa seria uma hipótese a ser explorada em atividade pedagógica para a formação do artista teatral.

\section{BIBLIOGRAFIA CITADA:}

ARRUDA, Rejane Kasting. Apropriação de texto: um jogo de imagens. (2009a) Dissertação de Mestrado. São Paulo, ECA/USP. - Jogo e escrita no trabalho com o texto dramático: relato de uma experiência em diálogo com a tradição. In: SILVA, Armando Sérgio (org). CEPECA: Uma oficina de pesquisAtores. São Paulo, Associação dos Amigos da Praça, 2010a. . Subpartitura e texto-dado: a troca para a inscrição do impulso. Anais da V Reunião Científica da ABRACE, São Paulo, ECA/USP, 2009b. . Anteparo e impressão digital, a hipótese de um par fundamental. Anais do VI Congresso da ABRACE. São Paulo, ECA/USP, 2010b A função do manuscrito nas artes cênicas: testemunho e reflexões de uma pesquisatriz. Anais do X Congresso Internacional de Critica Genética, POA, 2010c.

- A bipótese de uma estrutura na diversidade dos jogos de criação atoral. Araraquara, Revista de Cultura Artística, ano 4, vol. 01.

KHAN, François. Reflexões sobre a prática da memória no ofício do ator de teatro. Revista Sala Preta, ECA/USP, v. 9, 2009.

KUSNET, Eugenio. Ator e método. São Paulo, Ed. Hucitec, 1992.

LACAN, Jacques. O seminário: livro 23, O sinthoma. Rio de Janeiro, Jorge Zahar Ed., 2007. Lituraterra. In: Outros escritos. Rio de Janeiro, Jorge Zahar Ed., 2003.

LEHMANN, Hans-Thies. O teatro pós-dramático. São Paulo, Cosac Naify, 2007. SILVA, Armando Sérgio. Interpretação: uma oficina da essência. In: SILVA, Armando Sérgio (org.) CEPECA: uma oficina de pesquisAtores. São Paulo, Associação dos Amigos da Praça, 2010.

SOLER, Collete. O "corpo falante". In: FINGERMANN, Dominique. (org.) Caderno de Stylus, n.1. Rio de Janeiro, Internacional dos Fóruns do Campo Lacaniano, 2010.

SPOLIN, Viola. O jogo teatral no livro do diretor. São Paulo, Perspectiva, 2004. 
Abstract: The chalenge of scene authonomy makes us think about the scenic body. Recognizing the significants of poetry where they can be written, we must go through the linkage with language and what from the language scapes - some unsaid from which the scenic corpus makes semblant, making itself as figuration of the Real - so that we can work the hypothesis of a "pedagogy of decomposition" of different esthetics and the experimentation of styles.

Keywords: theater creation; actors pedagogy; contemporary theater. 